\title{
PARANEOPLASTIC RETINOPATHY ASSOCIATED WITH METASTATIC CUTANEOUS MELANOMA OF UNKNOWN PRIMARY SITE
}

\author{
HAYYAM KIRATLI ${ }^{1}$, CHARLES E. THIRKILL ${ }^{2}$, SEVGUL BILGIÇ $^{1}$, BORA ELDEM $^{1}$ and \\ ARMAN KEÇECI ${ }^{1}$ \\ Ankara, Turkey and Sacramento, California
}

\begin{abstract}
SUMMARY
Purpose: To describe further the clinical and immunological features of cutaneous melanoma-associated retinopathy, which is an infrequent form of paraneoplastic syndrome.

Methods: We studied the salient clinical and immunological aspects of a 66-year-old man with metastatic cutaneous melanoma to lymph nodes of unknown primary site who developed melanoma-associated retinopathy.
\end{abstract}

Results: There was gradual loss of vision in the left eye. Colour vision and night vision were not affected. Visual fields showed arcuate defects. A full-field electroretinogram demonstrated attenuation of the b-wave amplitude in the left eye. The a-wave was intact. Indirect immunofluorescence techniques showed that the antibody reactions took place mainly in the outer plexiform layer of the retina.

Conclusions: Bipolar cells seem to be the target in melanoma-associated retinopathy. Contrary to previous reports, night blindness may not be a universal finding.

Paraneoplastic retinopathy associated with cutaneous melanoma, or melanoma-associated retinopathy (MAR) syndrome, is a recently recognised cause of various visual disturbances in patients afflicted with skin melanoma in the absence of metastases to intraocular structures or posterior visual pathways. This disorder is characterised by sudden onset of night blindness, sensation of pulsating lights, central visual field defects and b-wave abnormalities in the electroretinogram (ERG). ${ }^{1,2}$ The exact causative factors for these symptoms and findings are still largely unknown. The clinical and immunological

From: ${ }^{1}$ Department of Ophthalmology, Hacettepe School of Medicine, Ankara, Turkey; ${ }^{2}$ University of California, Davis Ophthalmology Research, Sacramento, California, USA.

Correspondence to: Hayyam Kiratli, MD, Hacettepe University, Göz ABD Sihhiye 06100, Ankara, Turkey. Fax: (90-312) 3094101. features of a patient with this rare syndrome are described here.

\section{CASE REPORT}

A 66-year-old man without any prior systemic or ocular problems presented with the complaint of mild visual loss of recent onset in his left eye. He had experienced occasional flashing lights but had no difficulty with night vision. A few days earlier an incisional biopsy had been done from his right axillary region, where rapid enlargement of four or five lymph nodes each measuring $3 \times 2 \times 2 \mathrm{~cm}$ was noticed.

His best corrected visual acuity was $6 / 9$ in the right eye and 6/18 in the left eye. There was no afferent pupillary defect. Results of colour vision testing on the Lanthony 40 hue test were normal. Slit lamp examination and ophthalmoscopy of both eyes were unremarkable. Central $30^{\circ}$ automated perimetry showed arcuate defects in the inferior and superior quadrants in both eyes, more pronounced in the left eye (Fig. 1). Intravenous fluorescein angiography showed normal prefilling and transit phases in both eyes. In the recirculation phase, a few areas of retinal pigment epithelial (RPE) window defects were discernible in both maculae. The late phase of the study was unremarkable. Full-field ERG demonstrated that the amplitude of the b-wave from the left eye was attenuated below 3 standard deviations of our laboratory normals. The a-wave was preserved. The implicit times of the components of the ERG were normal. ERG recordings of the right eye were within normal limits. Magnetic resonance imaging (MRI) of the orbits and head was normal.

Meanwhile, histopathological examination of the excised lymph nodes showed metastatic melanoma. An extensive investigation failed to reveal the primary site. The patient was then begun on a chemotherapy regimen. Six months later his systemic 


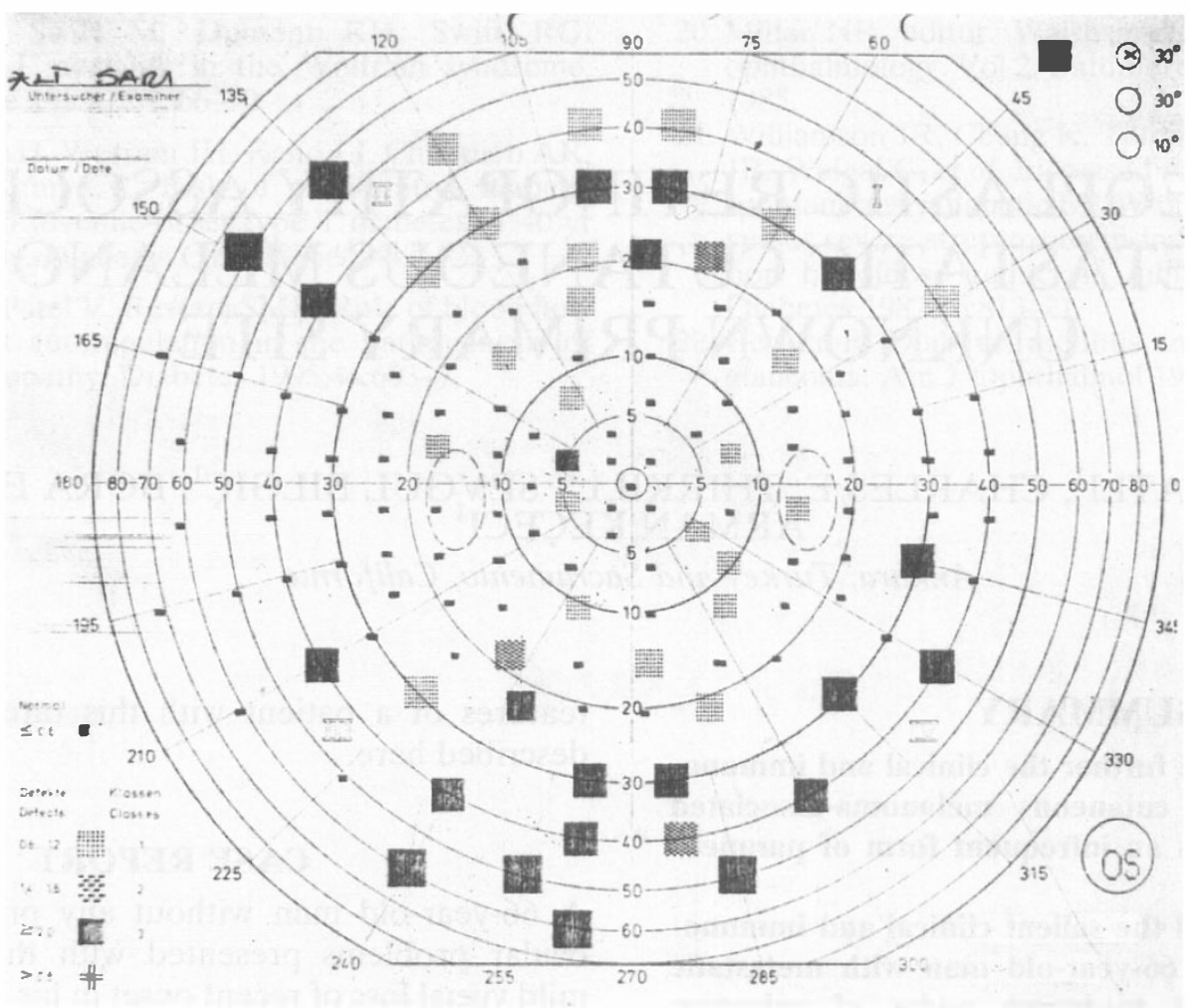

(a)

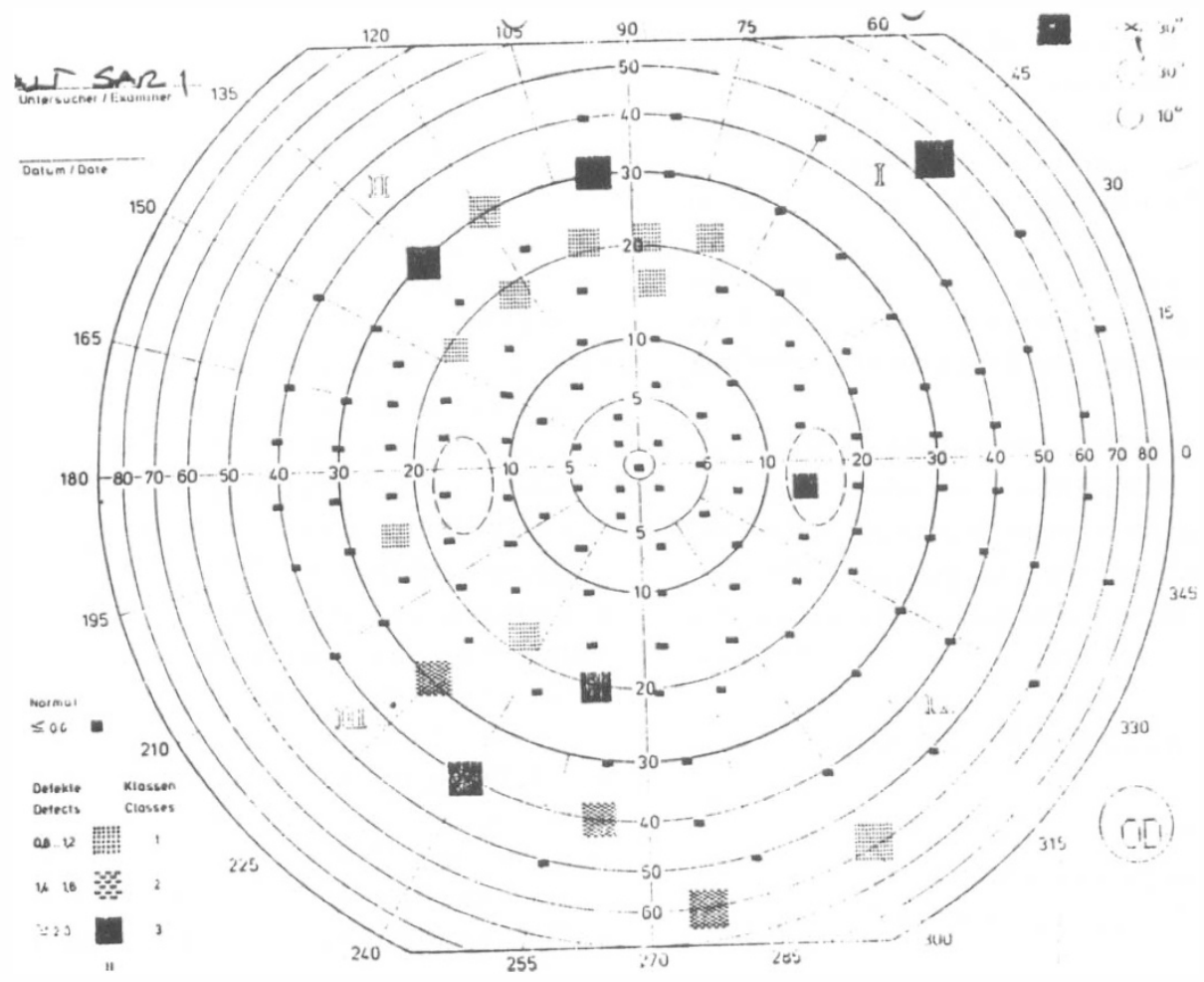

(b)

Fig. 1. (a) Automated perimetry of the left eye showing inferior and superior arcuate visual field defects. (b) Less extensive inferior and superior arcuate defects are observed in the right visual field. 


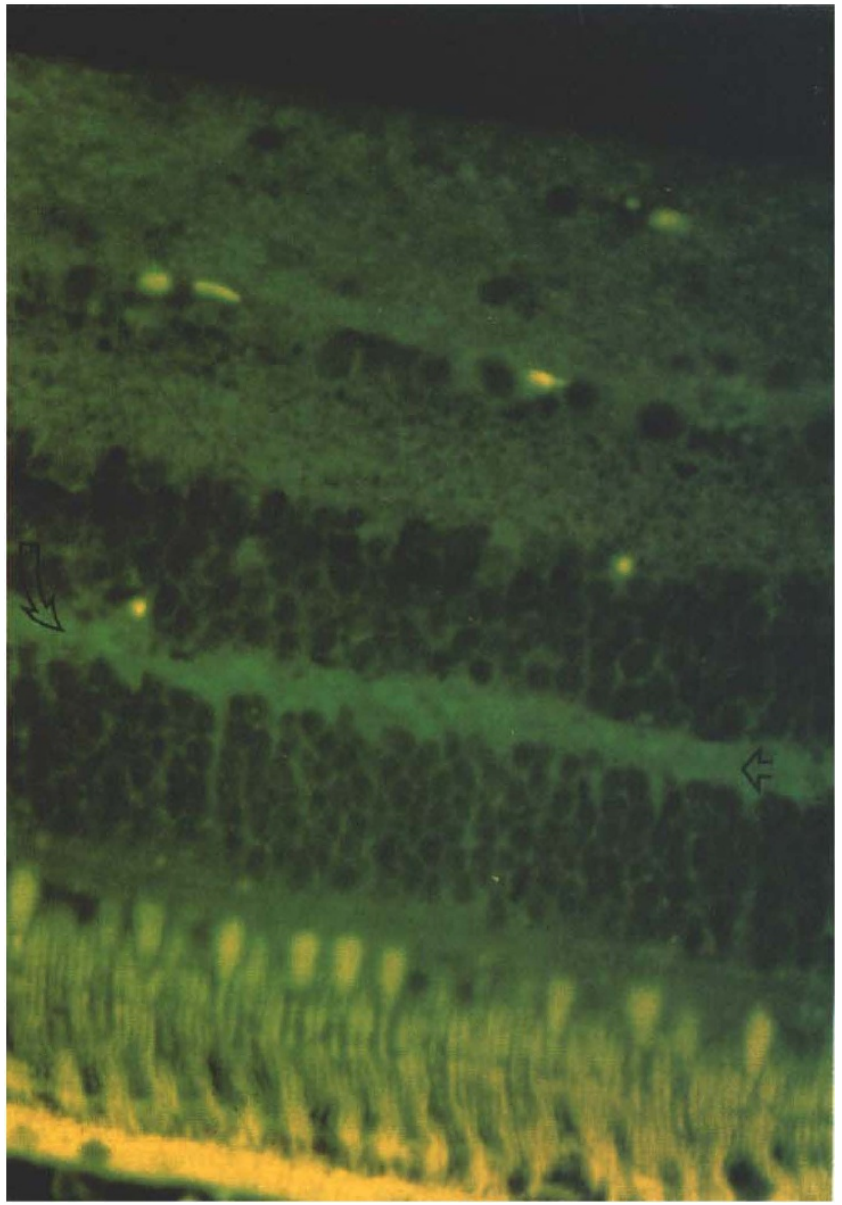

(a)

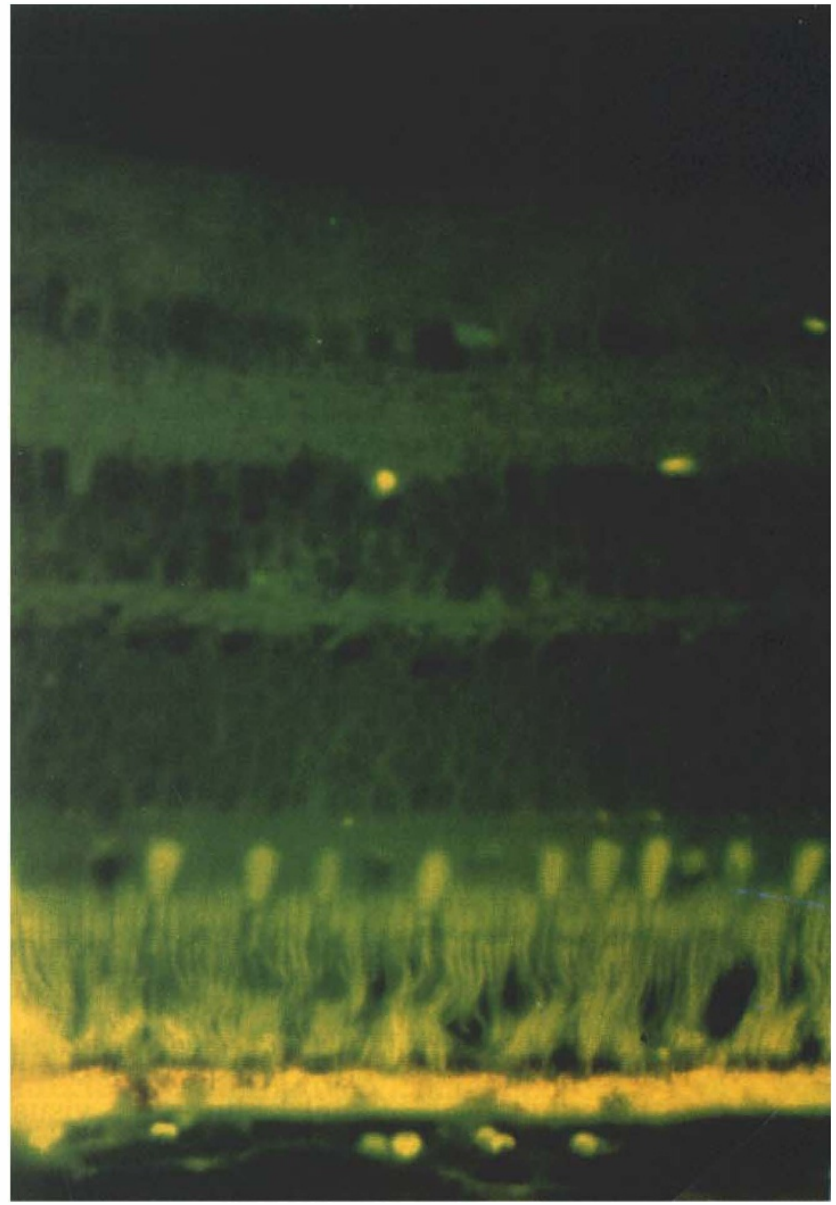

(b)

Fig. 2. (a) Photomicrograph of a section of rhesus monkey eye showing that the antibody interactions are confined to the outer plexiform layer (arrows) located between the inner and outer nuclear layers, the anatomical site of axons and dendrites of bipolar and amacrine cells. (b) Comparison control showing lack of any comparable antibody reactions in normal human serum evaluated at a dilution of 1:100 using indirect immunofluorescence.

status was stable and there was no change in his visual function and other ocular findings.

His serum was sent to the Thirkill Laboratory at the University of California Davis Ophthalmology Research, where it was evaluated for antibody reactions with retinal cells by indirect immunofluorescence. This sample serum was prepared before the patient received chemotherapy. The serum was evaluated at a dilution of 1:400 using $6 \mu \mathrm{m}$ sections of formalin-fixed, paraffin-embedded rhesus monkey eyes and fluorescein-conjugated, goat anti-human polyvalent immunoglobulins. The autoantibody reactions were localised on cellular elements found in the outer plexiform layer lying between the inner and outer nuclear layers of the retina (Fig. 2).

\section{DISCUSSION}

There are various types of paraneoplastic retinopathy reported in the literature, all resulting from the remote effects of different forms of cancer, involving distinct cell layers of the retina, without intraretinal metastases. ${ }^{3-5}$ Although the biochemical effects of neoplasia can be profound, and could include retinal toxicity, interest has come to focus on the unusual immunological reactions these patients manifest. One specific subgroup, those with the cancerassociated retinopathy (CAR) syndrome, ${ }^{6}$ are identified by their autoantibody reactions with the $23 \mathrm{kDa}$ photoreceptor protein 'recoverin'? This substance is a calcium binding protein found in certain cells of the retina. ${ }^{6}$ To date, this immunological grouping of retinopathy patients, based upon an expression of hypersensitivity to a solitary retinal protein, is the only example of a defined form of vision loss linked with a single, recognised autoantigen. ${ }^{8}$

We found that the principal region of antibody binding was the outer plexiform layer and, to a lesser extent, part of the inner nuclear layer of the retina. The outer plexiform layer contains in its outer twothirds the axons of photoreceptor rods and cones, enveloped by Müller cell outer segments. ${ }^{9}$ The inner one-third of this layer is truly plexiform and the major components here are the intertwining den- 
drites of bipolar cells with the axons of amacrine and horizontal cells. ${ }^{9}$ This layer of axons and dendrites lies very close to bipolar cells of the inner nuclear layer. ${ }^{9}$ Our immunological findings are in agreement with those previously reported by Milam et al. ${ }^{10}$ and Weinstein et al. ${ }^{1}$ in their evaluations of the autoantibody content of patients with melanoma-associated retinopathy, the MAR syndrome. These investigators specifically implicate retinal bipolar cells in the autoantibody reactions of MAR patients, but the identity of the retinal antigen(s) involved remains unknown. Defective functioning at the level of rod bipolar cells would impair the signal transmission from rod photoreceptors and result in reduced ERG b-wave amplitude but a preserved a-wave. ${ }^{10}$ Alexander et al. ${ }^{11}$ have shown that 'on' response defects in intraretinal signal transmission result from the reaction against a certain subset of bipolar cells (depolarising bipolar cells) in MAR. On the other hand, the 'off' response, generated by cone photoreceptors and hyperpolarising bipolar cells, was found to function normally. ${ }^{11}$ Hypothetically, this selective involvement of different subsets of bipolar cells may play a role in various clinical manifestations of MAR.

In MAR syndrome, patients almost invariably present with acute onset of night blindness, visual loss and a sensation of shimmering lights. ${ }^{1,2,10-13}$ The night blindness is reported to be severe and permanent. $^{2}$ Temporal asymmetry of involvement between the eyes is a recognised feature of the disease. ${ }^{2,10}$

Interestingly, all the patients reported in the literature are men. ${ }^{1,2,10-14}$ Visual symptoms usually developed 2-4 years after the diagnosis of cutaneous melanoma. ${ }^{2}$ Except for the case reported by Rush, ${ }^{12}$ all the patients had a known primary melanoma site. Acute Vogt-Koyanagi-Harada like syndrome has been reported in a patient with metastatic cutaneous melanoma. ${ }^{15}$ However, unlike MAR, where the ERG a-wave usually remains unchanged, that patient had markedly diminished ERG a- and b-waves.

Our patient differs slightly from those previously described in that he did not experience night blindness, either at the onset of his disease or during his follow-up after chemotherapy. Furthermore, his visual disturbances coincided with the discovery of metastatic melanoma, the primary site of which could not be determined.

The localised immunological reactions we describe in our metastatic melanoma patient with visual loss, support the findings of others, ${ }^{1,10}$ and should spur the search for comparable, single antigen involvement in patients with the MAR syndrome. As more patients with this rare syndrome are reported, it is likely that different clinical expressions and aspects of the disease will be elucidated.

This work was supported in part by NEI EYO 9063 the University of California Tobacco-Related Disease Research Program and Research to Prevent Blindness.

Key words: Cutaneous melanoma, Paraneoplastic syndrome, Retina, Melanoma-associated retinopathy.

\section{REFERENCES}

1. Weinstein JM, Kelman SE, Bresnick GH, Kornguth SE. Paraneoplastic retinopathy associated with antiretinal bipolar cell antibodies in cutaneous malignant melanoma. Ophthalmology 1994;101:1236-43.

2. Kim RY, Retsos, S, Fitzke FW, Arden GB, Bird AC. Cutaneous melanoma associated retinopathy. Ophthalmology 1994;101:1837-43.

3. Kornguth SE, Kalinke, T, Grunwald GB, Schutta H, Dahl D. Antineurofilament antibodies in the sera of patients with small cell carcinoma of the lung and visual paraneoplastic syndrome. Cancer Res 1986;46:2588-95.

4. Grunwald GB, Kornguth SE, Towfighi J, Sassani J, Simmonds MA, Housman CM, Papadopoulos N. Autoimmune basis for visual paraneoplastic syndrome in patients with small cell lung carcinoma: retinal immune deposits and ablation of retinal ganglion cells. Cancer 1987;60:780-6.

5. Sawyer RA, Selhorst JB, Zimmerman LE, Hoyt WF. Blindness caused by photoreceptor degeneration as a remote effect of cancer. Am J Ophthalmol 1976; 81:606-13.

6. Thirkill CE. Cancer associated retinopathy, the CAR syndrome. Neuro-ophthalmology 1994;14:297-323.

7. Thirkill CE, Tait RC, Tyler NK, Roth AM, Keltner JL. The cancer-associated retinopathy antigen is a recoverin-like protein. Invest Ophthalmol Vis Sci 1992;33:2768-72.

8. Gery I, Chanaud NP, Anglade E. Recoverin is highly uveitogenic in Lewis rats. Invest Ophthalmol Vis Sci 1994:35:3342-5.

9. Fine B, Yanoff M. Ocular histology: a text and atlas. 2nd ed. New York: Harper and Row, 1979:82-93.

10. Milam AH, Saari JC, Jacobson SG, Lubinski WP, et al. Autoantibodies against retinal bipolar cells in cutaneous melanoma associated retinopathy. Invest Ophthalmol Vis Sci 1993;34:91-100.

11. Alexander KR, Fishman GA, Peachy NS, Marchese AL, Tso MOM. 'On' response defect in paraneoplastic night blindness with cutaneous malignant melanoma. Invest Ophthalmol Vis Sci 1992;33:447-83.

12. Rush JA. Paraneoplastic retinopathy in malignant melanoma. Am J Ophthalmol 1993;115:390-1.

13. Berson EL, Lessel S. Paraneoplastic night blindness with malignant melanoma. Am J Ophthalmol 1988;106: 307-11.

14. Ripps H, Carr RE, Siegel IM, Greenstein VC. Functional abnormalities in vincristine induced night blindness. Invest Ophthalmol Vis Sci 1984;25:787-94.

15. Gass JDM. Acute Vogt-Koyanagi-Harada like syndrome occurring in a patient with metastatic cutaneous melanoma. In: Saari KH, editor. Uveitis update: proceedings of the international symposium on uveitis. Amsterdam: Elsevier, 1984:407-8. 